ИЗВЕСТИЯ АКАДЕМИИ НАУК ЭСТОНСКОИ ССР. ТОМ ХVIII ХИМИЯ * ГЕОЛОГИя. 1969, № 2

K. ORVIKU, K. ORVIKU jun.

\title{
UBER DIE BESTÄNDIGKEIT DER ENTWICKLUNG DER KÜSTEN IM ESTLÄNDISCHEN KÜSTENGEBIET IN DER SPÄTGLAZIALZEIT, IM HOLOZÄN UND IN DER GEGENWART
}

Die in den letzten Jahren durchgeführten Untersuchungen der gegenwärtigen Küsten Estlands und ihrer Dynamik haben es ermöglicht, die Küsten Nordwest-Estlands und der Inseln des West-Estländischen Archipels als ein selbständiges Estländisches Küstengebiet der Ostsee $\mathrm{zu}$ betrachten. Gleichzeitig wurde bewiesen, daß die eigentümlichen Entwicklungszüge dieser Küsten auch für die spätglazialen und holozänen Küsten desselben Gebietes charakteristisch waren (Orviku K., Orviku Kaarel, 1961; Орвику К. К., Орвику Каарел, 1965). Neue Untersuchungen der 'gegenwärtigen (Орвику К. мл., 1963, 1965, 1966) und der alten (Раукас, Кессел, Эльтерманн, 1965; Кессел, Раукас, 1967) Küsten Estlands lieferten neue Angaben, die es erlauben, die Eigenart der Entwicklung der Küsten des Estländischen Küstengebietes besser als früher zu schildern. Im folgenden wird der Versuch gemacht, zu zeigen, wie die stattgefundenen tektonischen Bewegungen der Erdkruste, die alte Bodengestaltung, die paläozoischen Gesteine und die quartären Ablagerungen bei der fortwährenden Entwicklung der Küsten mitgewirkt haben.

Ungeachtet der Änderungen im hydrodynamischen Regime der $\mathrm{Ge}$ wässer des Ostseebeckens, - Änderungen, welche vom spätglazialen und holozänen Klimawechsel verursacht wurden, kann man das hydrodynamische Regime und seine Einwirkung auf die Entwicklung der Küsten im Estländischen Küstengebiet von der Spätglazialzeit an und bis in die Gegenwart im allgemeinen als ziemlich beständig ansehen. Bereits in den dreißiger Jahren dieses Jahrhunderts ist festgestellt worden, daß im WestEstländischen Küstengebiet die Längsachsen der Einzeldünen in den Stranddünenketten verschiedenen Alters eine nordöstliche Richtung haben, was dafür spricht, daß sie von starken südwestlichen Winden, die hier auch heute vorherrschen, aufgehäuft wurden (Orviku, 1933). Auch neuere Untersuchungen ergeben das gleiche Resultat (Eltermann, Raukas, 1966). Dementsprechend kann man annehmen, daß im Estländischen Küstengebiet wahrscheinlich seit dem Stadium des Baltischen Eisstausees eine ähnlichezyklonale Tätigkeit, bzw. ähnlicher Wellengang usw. geherrscht hat, wie in der Gegenwart.

Durch zahlreiche Untersuchungen der alten Küstenbildungen und durch. wiederholte Präzisionsnivellierungen wurde festgestellt, daß die Entwicklung der Küsten Estlands im Spätglazial, im Holozän und in der: 
Gegenwart unter den Bedingungen der summarischen Hebung der Erdkruste des Territoriums stattgefunden hat. Insbesondere gilt das fürs. Estländische Küstengebiet, wo die Hebung am intensivsten war. Davon überzeugt uns der Verlauf der Isobasen der alten Strandlinien (Kessel, 1961; Кессел, Раукас, 1967 и. а.), desgleichen der Isobasen der gegenwärtigen Bewegungen der Erdkruste (Желнин, 1964) (Аbb. 1).

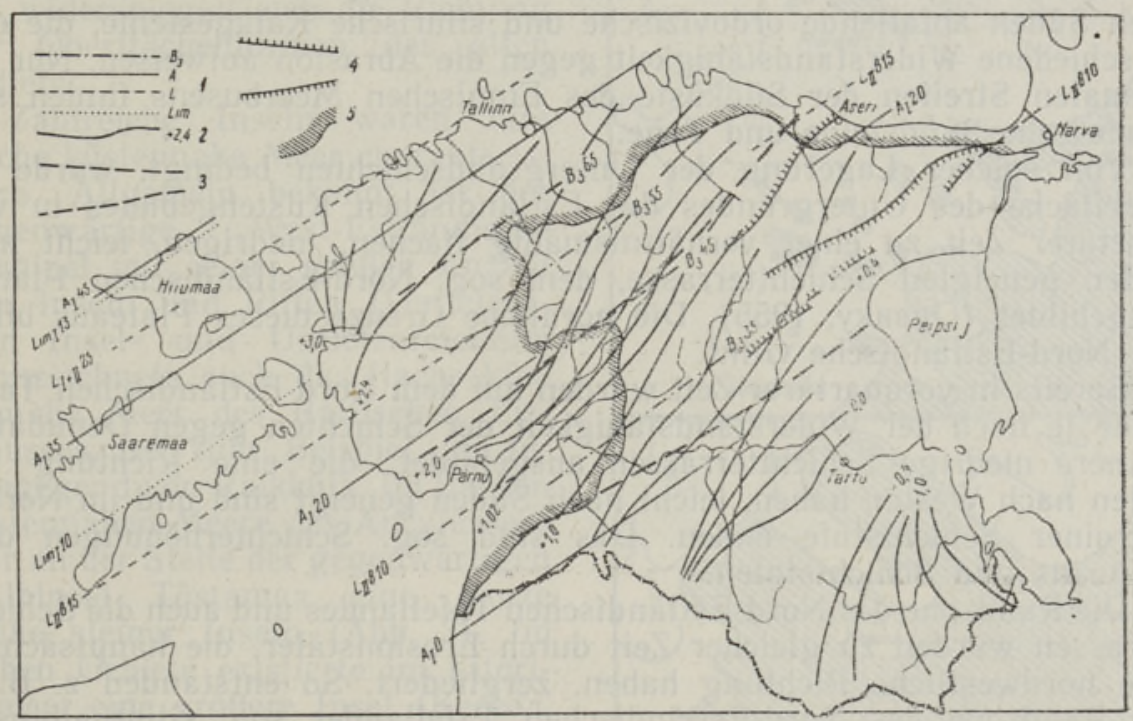

Abb. 1. Isobasen der alten Küsten (1) der Ostsee in Estland. Isobasen der gegenwärtigen tektonischen Bewegungen der Erdkruste (2), tektonisch aktive Zone nordöstlicher Richtung (3) und die tektonischen Störungen in den paläozoischen Schichten (4). Es wird die Küstenlinie des Baltischen Eisstausees BII (5) gegeben (nach Kessel 1961; Желнин, 1964; Мийдел, 1967; Орвику, 1960; Пярна, 1960).

Man kann sogar sagen, daß die südöstliche Grenze des Estländischen: Küstengebietes (etwa die Linie Pärnu-Aseri) in großen Zügen mit der Zone der intensiveren tektonischen Bewegung, die nordöstlich gerichtet ist, zusammenfällt. Bereits im Paläozoikum entstanden in dieser Zone flexurartige Strukturen nordöstlicher Richtung mit Amplituden bis 20 Meter (Орвику, 1960; Мийдел 1966 ш. а.). In derselben Zone verändert sich bedeutend der Gradient der spätglazialen Strandlinien - hier findet man die gotiglaziale Biegungszone (Пярна, 1960). In dieser Zone ist auch durch wiederholte Präzisionsnivellierungen eine bedeutende Größenänderung des Gradients der gegenwärtigen Hebung der Erdkruste festgestellt worden (Желнин, 1964). In Estland wie auch in den benachbarten Ländern hat das Niveau der Gewässer, die im Ostseebecken existiert haben, recht große Schwankungen erfahren, was durch verschiedene Bedingungen verursacht wurde (Кессел, Раукас, 1967). Dieser Schwankungen ungeachtet kann man hier ein summarisches Zurückweichen des Meeres, verursacht durch die tektonische Hebung der Erdkruste, konstatieren. Besonders eindeutig geschah das in den letzteren 5000 Jahren, d. i. von der zweiten Hälfte des Litorinastadiums angefangen.

Die Beständigkeit der Hebung der Erdkruste hat in bezug auf die Entwicklung der Küsten eine besondere Bedeutung, namentlich wenn man den geologisch-geomorphologischen Bau des Territoriums in Betracht zieht. In das Gebiet der Wellentätigkeit gerieten stets neue Teile des. 
Meeresbodens. Diese blieben aber nur kürzere Zeit der Einwirkung der Küstenprozesse ausgesetzt; durch die fortdauernde Hebung wurden sie recht bald Teile des Festlandes. Unter solchen Bedingungen konnte nur wenig Abrasionsmaterial entstehen, die Küstenablagerungen konnten sich in geringer Mächtigkeit anhäufen; die betreffenden Flächen sind klein.

*

Den Untergrund des Estländischen Küstengebietes bilden schwach nach Süden abfallende ordovizische und silurische Kalkgesteine, die eine verschiedene Widerstandsfähigkeit gegen die Abrasion aufweisen. Nur auf schmalen Streifen der Südküste des Finnischen Meerbusens finden sich kambrische Sandsteine und Tone.

Von solcher Lagerung der Untergrundschichten bedingt, wurde die Oberfläche des Untergrundes des Estländischen Küstengebietes in vorquartärer Zeit zu einer verhältnismäßig flachen, niedrigen, leicht nach Süden geneigten Schichtterrasse, dem sog. Nord-Estländischen Plateau ausgebildet (Орвику, 1955). Die nördliche Grenze dieses Plateaus bildet der Nord-Estländische Glint.

Bereits in vorquartärer Zeit wurden auf dem Nord-Estländischen Tafellande je nach der Widerstandsfähigkeit der Schichten gegen Denudation kleinere niedrige Schichtterrassen ausgebildet, die eine Richtung von Osten nach Westen haben, leicht nach Süden geneigt sind und im Norden mit einer Schichtstufe enden. Das sind sog. Schichterhöhungen oder -plateaus und Schichtstufen.

Die Randzone des Nord-Estländischen Tafellandes und auch die Schichtterrassen wurden zu gleicher Zeit durch Erosionstäler, die hauptsächlich eine nordwestliche Richtung haben, zergliedert. So entstanden z. B. in der Randzone des Nord-Estländischen Tafellandes sog. Glinthalbinseln und Glintbuchten (Tammekann, 1940), welche im westlichen Teile dieser Randzone besonders gut ausgebildet sind.

Das vorquartäre Relief des Untergrundes wurde im Pleistozän durchs Inlandeis einigermaßen umgearbeitet, wodurch das vorquartäre Relief stellenweise drumlinisierten Charakter bekam. Obwohl die denudierende Tätigkeit des Inlandeises bei der Umformung des vorquartären Reliefs eine bestimmte Rolle spielte, sind die Grundzüge des vorquartären Reliefs bis zur Gegenwart erhalten geblieben.

War die Flachheit und die schnelle Abwechslung kleiner und verhältnismäßig flacher Erhöhungen bereits für die vorquartäre Oberflächengestaltung charakteristisch, so noch mehr fürs glaziale Relief, welches hier im Spätpleistozän entstand. Auch die Verbreitung und Mächtigkeit der glazialen Ablagerungen zeigt hier eine schnelle Abwechslung.

Diese flache mosaikartig gebaute alte Oberflächengestaltung hat auf die Entwicklung der Küsten im Estländischen Küstengebiet eine bedeutende Wirkung ausgeübt. Diese Wirkung hat von der Spätglazialzeit an und bis in die Gegenwart stets in einer Richtung stattgefunden, was ebenfalls die Beständigkeit der Entwicklung der Küsten bestimmt hat.

Das ebene Relief des Estländischen Küstengebietes, welches von der Wasserscheide des Nord-Estländischen Tafellandes in der Richtung der Randzone des Tafellandes nach und nach herabfällt, bedingte $\mathrm{zu}$ allen Zeiten das Vorhandensein des küstennahen seichten Meeres, bzw. der Flachmeerküsten. Wegen der Seichtigkeit des küstennahen Meeres verursachten auch flache kleine, relativ niedrige Unebenheiten des Reliefs eine verhältnismäßig starke Zergliederung der Küsten (es existierten stets zahlreiche Halbinseln und Buchten), im küstennahen Meer aber bestanden viele Inseln verschiedener Größe. Im folgenden werden nur einzelne entsprechende Beispiele angeführt. 
Stark zergliedert war zum Beispiel die südöstliche Küste des Baltischen Eisstausees zwischen Varbola und Voose, wo die Halbinseln und Buchten eine nordwestliche Richtung hatten. Dieselbe Richtung hatten sie auch im Ancylussee und im Litorinameer, und haben auch im gegenwärtigen Meere im Gebiet westlich von Tallinn (Abb. 2) (Кессел, 1961; Кессел, Раукас, 1967). In dieser nordwestlichen Richtung der Halbinseln und Buchten widerspiegelt sich die Richtung der Oberflächenformen des alten Reliefs.

Zahlreiche Inseln waren fürs flache küstennahe Meer charakteristisch. Allgemein bekannt ist der gegenwärtige West-Estländische Archipel mit seiner großen Anzahl von Inseln und Riffen (Untiefen). Der Insel- und Untiefenreichtum kennzeichnete auch das flache küstennahe Meer des Baltischen Eisstausees, so zum Beispiel in der Umgegend von Raikküla. Im flachen küstennahen Meere des Ancylussees war an der Stelle der gegenwärtigen Halbinsel Tõstamaa eine ganze Reihe kleiner Inseln (Abb. 3). Im selben Gebiete existierte im Litorinameer eine größere Insel (Кессел, 1961; Кессел, Раукас, 1967). Die kleinen Tiefen des küstennahen Meeres, die zahlreichen Buchten mit seichtem Wasser, die vielen Inseln, Inselchen und Untiefen, auch die häufige Abwechslung der Tiefen im seichten küstennahen Meer, - das alles ist dem Charakter der alten Oberflächengestaltung geschuldet.

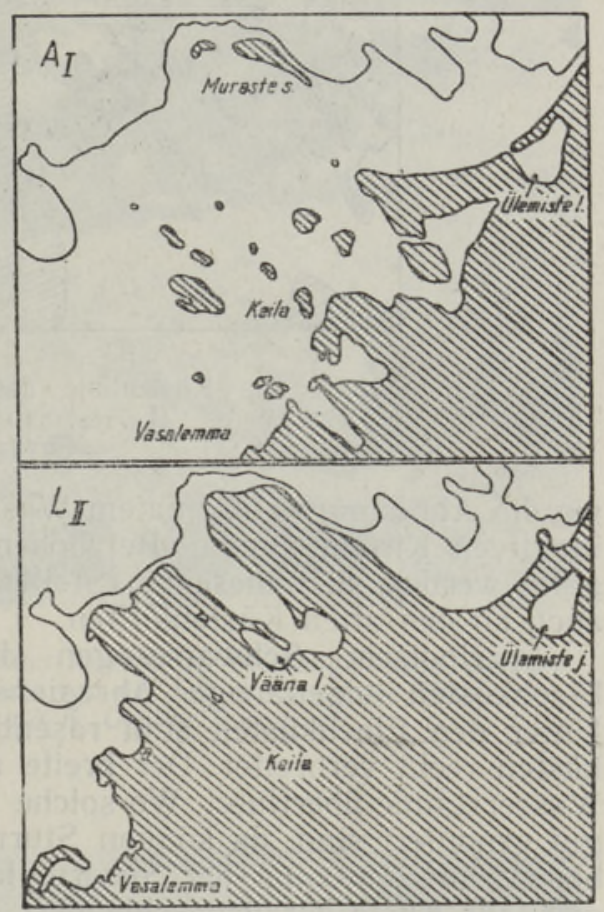

Abb. 2. Die Küstenlinie des Ancylussees $\left(\mathrm{A}_{\mathrm{I}}\right)$ und des Litorinameeres $\left(\mathrm{L}_{\mathrm{I} 1}\right)$ südwestlich von Tallinn (nach Кесcел, Раукас, 1967).

Infolge einer solchen Beschaffen-

heit der Küste ist die Intensität der Wellentätigkeit an verschiedenen Küstenabschnitten überaus verschieden. Der starke Wellengang des offenen Meeres erreicht nur da die Küste, wo die Tiefe des küstennahen Meeres relativ größer und die Küste den Wellen exponiert ist - das sind die Küstenvorsprünge der Inseln und Halbinseln, die dem offenen Meere exponiert sind. Die vielen Inseln und Untiefen haben viele leeseitige Küsten verursacht. Wegen der geringen Tiefen des küstennahen Meeres ist die Brandungszone von der Strandlinie ziemlich weit entfernt: auch bei starkem Wellengang erreichen nur verhältnismäßig kleine Wellen den Strand.

Die rasche Abwechslung der Intensität der Wellentätigkeit an den Küsten wird noch dadurch modifiziert, daß die Höhe der Meeresoberfläche unter der Einwirkung der andauernden Winde episodisch beträchtlich (bis 2 Meter) schwankt. Wo das Relief sehr flach ist, da ist der Strandstreifen und auch der Vorstrand recht breit.

Eine intensive Abrasion auf der Schorre und Akkumulation auf dem Strande vollzieht sich hauptsächlich bei hohem Wasserstande und starkem Wellengang. Man hat viele Beispiele an gegenwärtigen Küstenkliffent 


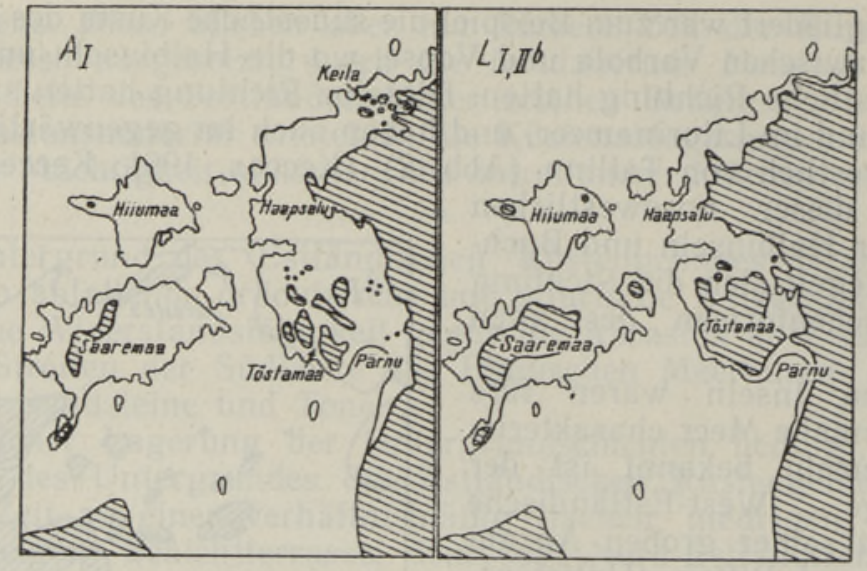

Abb. 3. Die Küstenlinie des Ancylussees $\left(A_{I}\right)$ und des Litorinameeres $\left(\mathrm{L}_{\mathrm{I}}, \mathrm{IIb}\right)$ in West-Estländ (nach Кесcел, Раукас, 1967).

wo die Abrasion bei normalem Wasserstande vollständig fehlt. so daß sie inaktiven Kliffen ähneln. Bei hohem Wasserstande und starkem Wellengang werden aber dieselben Steilküsten intensiv zerstört. So geschah es auch an den alten Küstenkliffen.

Aperiodische Schwankungen des Meeresspiegels verursachen auf Flachküsten eigenartige Abrasions- und Akkumulationserscheinungen. Unter den Flachküsten sind rasenbedeckte Küsten und flache Moränenküsten recht verbreitet. Der breite rasenbedeckte Strand wird bei hohem Wasserstande überflutet. Wo solche Küsten dem Wellengang einigermaßen gut exponiert sind, da können Sturmwellen bei hohem Wasserstande eine bedeutende Abrasion der Schorre leisten. Das Geröllmaterial wird dann quer zur Küste herausgeschleudert, bis zur Küstenlinie des Hochwassers, wo ein Strandwall angehäuft wird. So entstandene Strandwälle liegen abgesondert auf dem Strande und sind zuweilen hufeisenförmig (Abb. 4).

Das Schwächerwerden des Wellenganges in der Richtung zur Küste hin im flachen küstennahen insel- und buchtenreichen Meere, desgleichen eine bedeutende aperiodische Schwankung der Wasserfläche, was man an den gegenwärtigen Küsten des Estländischen Küstengebietes gut beobachten kann, waren auch den alten Küsten dieses Gebietes eigen und verursachten ähnliche spezifische Abrasions- und Akkumulationserscheinungen, wie es an den gegenwärtigen Küsten geschieht.

Es wurde bereits erwähnt, daß für die gegenwärtigen und die alten Küsten im Estländischen Küstengebiet starke Zergliederung und großer Inselreichtum charakteristisch sind. Das zeigt, daß die Küstenprozesse auf einem bestimmten Niveau infolge der tektonischen Hebung des Territoriums nur kurze Zeit tätig waren und es nicht dazu gekommen ist, die zergliederte Küste in eine Ausgleichküste $\mathrm{zu}$ verwandeln.

Es ist nachgewiesen worden, daß auf der gegenwärtigen Schorre unter den Küstenablagerungen die feinkörnigen Ablagerungen des Meeresgrundes fehlen - das spricht dafür, daß von denjenigen Teilen des Meeresgrundes, welche durch die tektonische Hebung in das Bereich der Küstenprozesse geraten, die feinkörnigen Ablagerungen abgespült und seewärts fortgetragen werden. Auch bei den alten Küsten hat man keine feinkörnige Ablagerungen des Meeresbodens gefunden - auch in der Vergangenheit wurden sie bei der Verschiebung der Küstenzone seewärts abgeschwemmt. 


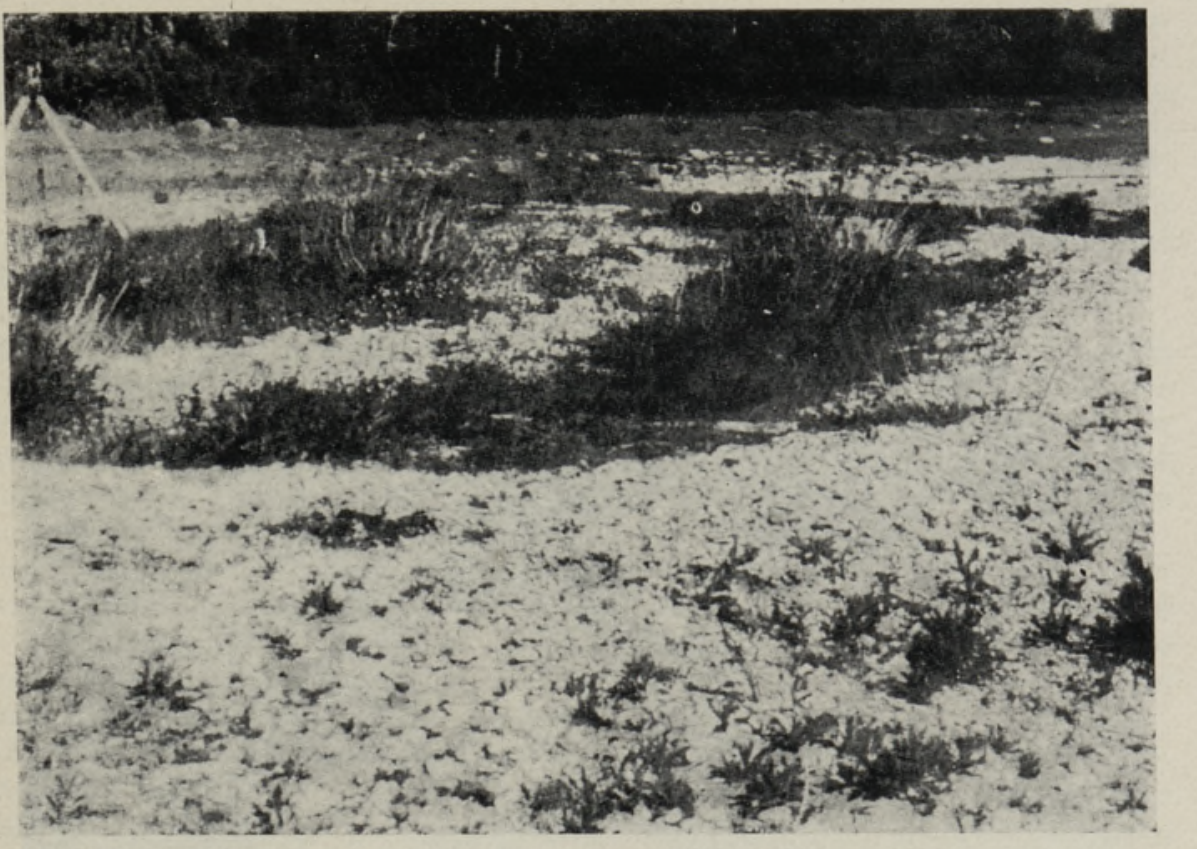

Abb. 4. Hufeisenförmiger Strandwall auf einer Insel in der Meerenge Muhu, welcher durch Herausschleudern des Schotters von der Schorre quer zur Küste entstanden ist. Photo K. Orviku jun.

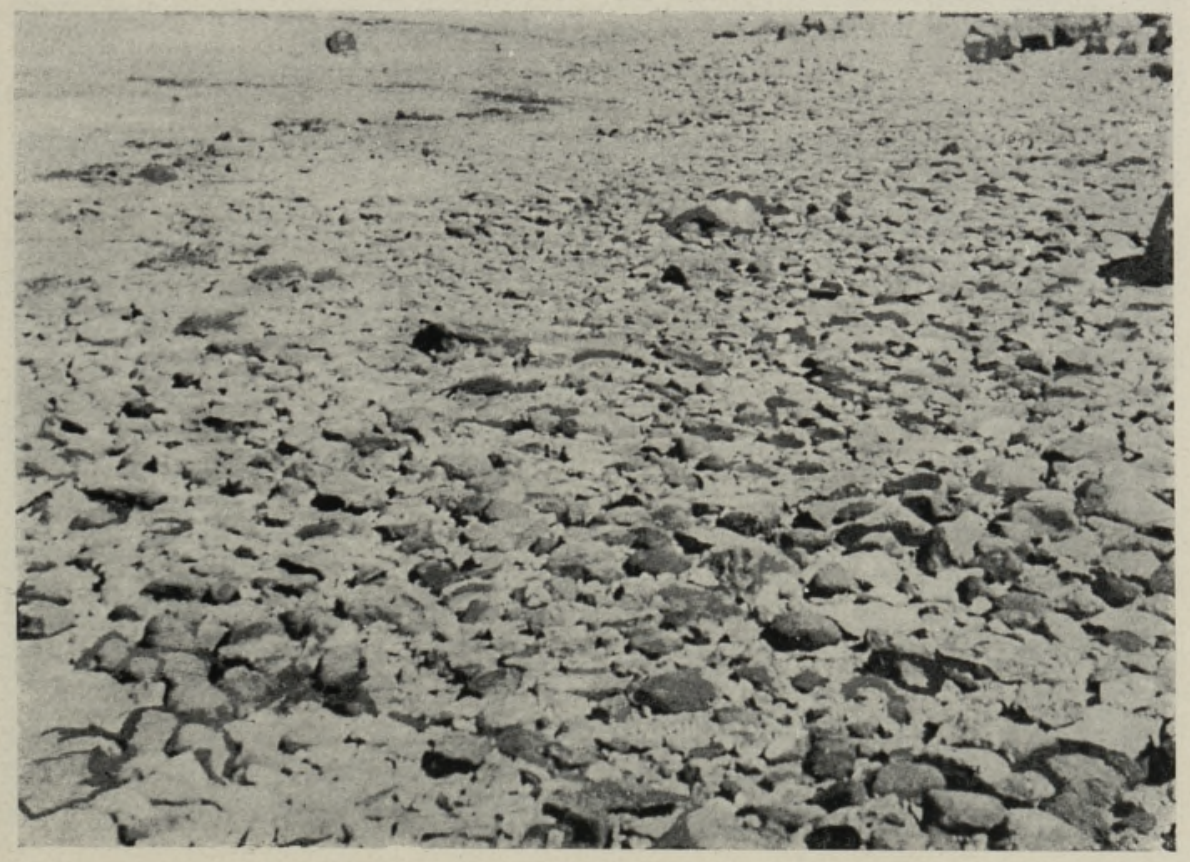

Abb, 5. Moränenküste mit Steinpflaster auf der Schorre auf der Insel Saaremaa. Photo K, Orviku jun. 


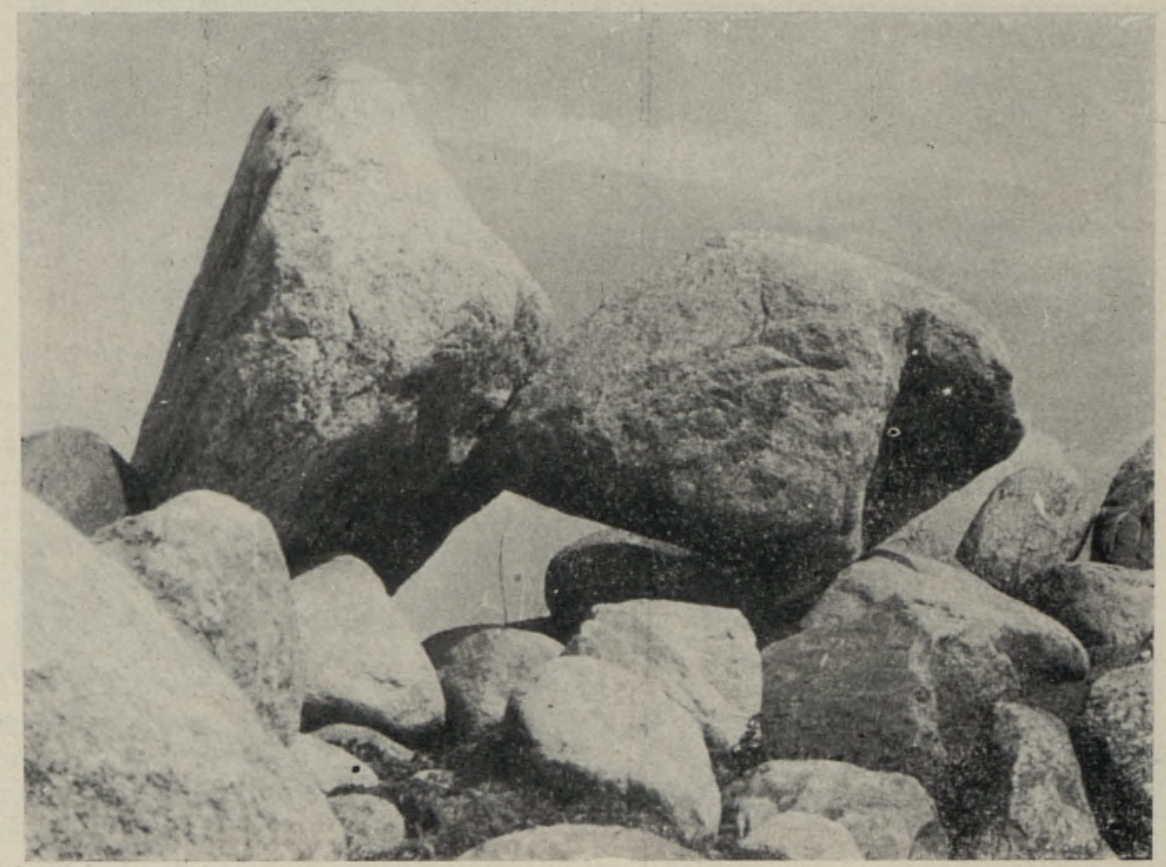

Abb. 6. Vom Meereis angehäufte erratische Blöcke auf der Moränenküste einer Insel in der Meerenge Muhu. Photo K. Orviku jun.

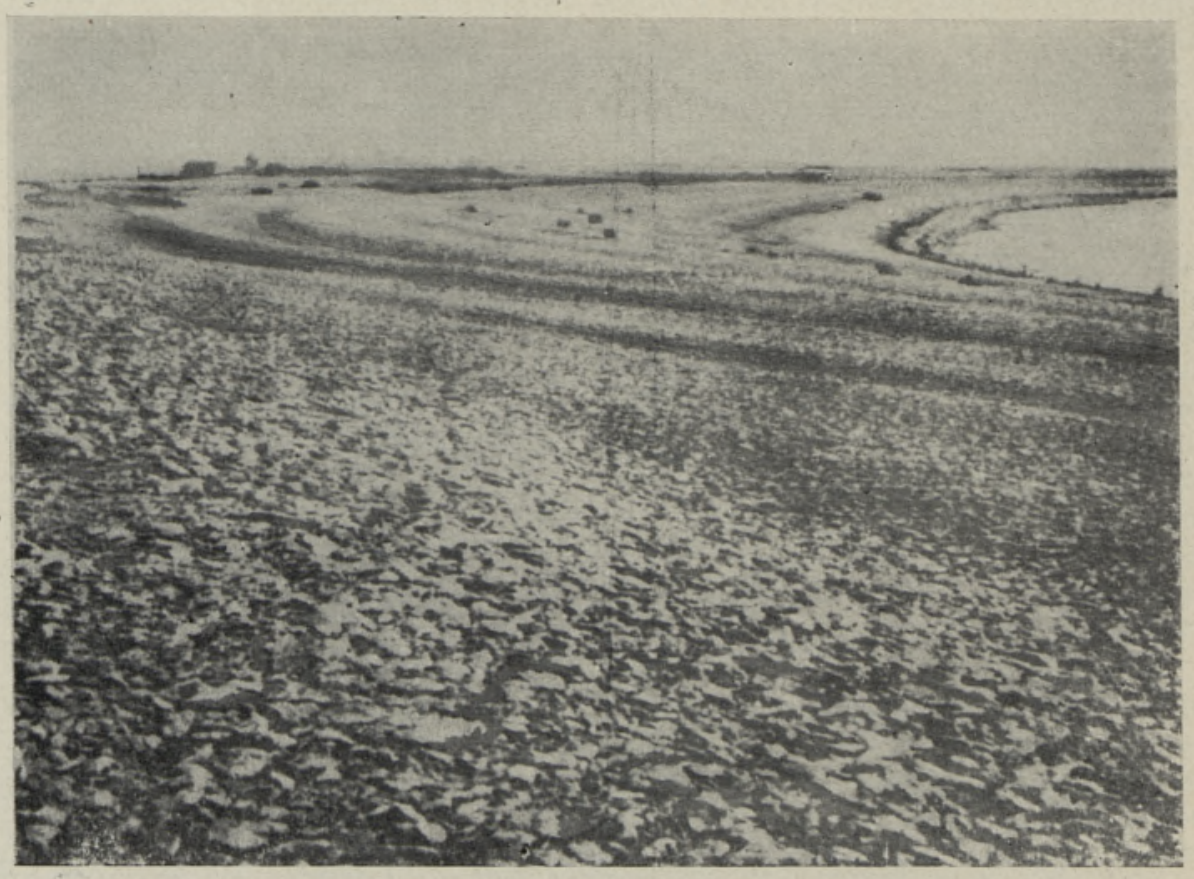

Abb. 7. Stufenartig angeordnete Strandwälle von Geröll an der Westküste der Halbinsel Sõrve (Saaremaa); das Geröll ist quer zur Küste von der Schorre herausgeschleudert worden. Photo K. Orviku. 
Auf den gegenwärtigen Abrasionsküsten findet man an zahlreichen Stellen eine Abrasionsterrasse, die in den Kalkgesteinen oder kambrischen Sandsteinen des Untergrundes ausgearbeitet ist. Das beweist, daß die dünne Deckschicht der Quartärablagerungen, gewöhnlich aus der Grundmoräne bestehend. durch die Wellentätigkeit abgewaschen worden ist. Auch auf den alten Meeresterrassen findet man an vielen Stellen kleinere oder größere Flächen, wo die Quartärablagerungen fast völlig fehlen und die Kalkgesteine des Untergrundes entblößt sind - das sind die Alvargebiete.

Noch öfter findet man auf dem Vorstrande und auch auf dem Strande gegenwärtiger Moränenküsten ein Steinpflaster (Abb. 5) - bei der Ábrasion der Moräne sind aus derselben die feinkörnigen Fraktionen ausgewaschen worden, und das verbliebene Material (Gerölle und Geschiebe, auch Blöcke) bildet über der Moräne eine dünne Schicht, die eine weitere Auswaschung der Moräne verhindert. An solchen Moränenküsten, aber auch am Strande andersartiger Küsten, findet man gewöhnlich auch Anhäufungen erratischer Blöcke (Орвику мл., 1965), die vom Treibeis auf den Strand geschoben worden sind (Abb. 6). Ebensolche Steinpflaster und Anhäufungen erratischer Blöcke findet man auch an vielen Stellen längs der alten Küsten.

Die starke Zergliederung der Küstenlinie bedingt eine rasche Abwechslung der Küsten: die mehr oder weniger exponierten Küsten der Halbinseln und Inseln sind gewöhnlich steilhängige Abrasionsküsten, meist Kliffe, die in geschichteten Kalkgesteinen ausgearbeitet sind. Solche finden sich aber nur auf kurzen Küstenstrecken. In ihrer nahen Nachbarschaft folgen Geröllküsten (Schotterküsten) mit schön ausgebildeten Strandwällen. Aber auch die Geröllküsten sind wenig ausgedehnt. Wo die Moräne oder die fluvio-glazialen Ablagerungen abradiert wurden, da findet man in der Nachbarschaft der Abrasionsküsten Sandküsten mit Vordünen. Das gleiche Bild sieht man auch an den alten Küsten. Nur an den alten Transgressionsküsten ist die Erstreckung der Steilküsten (Kliffe) und der darauf folgenden Geröll- oder Sandküsten größer und sie sind deutlicher ausgeprägt, weil die Küstenprozesse innerhalb der betreffenden Zonen länger angedauert haben und die Küste in einem größeren Umfang gleichgerichtet wurde (Кессел, Раукас, 1967).

Bei der Regression sind die Küstenprozesse innerhalb einer bestimmten Zone von relativ kurzer Dauer, die Menge des durch die Abrasion aufgearbeiteten Materials ist auf der Schorre und am Strande recht gering, die entsprechenden Sedimentströme längs der Küste sind schwach und die Ausschleuderung des Gesteinmaterials quer zur Küste von kleinem Umfang; dementsprechend entstehen an regressiven Küsten Akkumulationsformen von kleinem Ausmaß.

Wo der ebene Meeresboden flache Erhebungen trägt, da entstehen im küstennahen Meere bei der Senkung des Wasserspiegels erst Untiefen und Riffe, dann Inseln, welche sich bei weiterer Senkung des Wasserspiegels mit dem Festland vereinigen. Untersuchungen der heutigen Küsten zeigen, $\mathrm{da} \beta$ bei der Entstehung der Inseln und überall, wo neue Teile des ebenen Meeresbodens in das Bereich der Küstenprozesse geraten, die Abrasion der Schorre und das Ausschleudern des Gesteinmaterials quer zur Küste zuerst die Hauptrolle spielen (Орвику мл., 1966). Erst auf einer späteren Entwicklungsetappe der Felsenküste oder als bereits ein Kliff entstanden war, werden die Sedimentströme längs der Küste vorherrschend. Dieser Entwicklungsgang ist an den gegenwärtigen Küsten der kleinen Insel Vaika und auf den kleinen Inseln in den Meerengen des West-Estländischen Archipels gut zu verfolgen. Auch von den alten Küsten kennt man solche sog. „Auf- 
schüttungsinseln" mit ähnlichem Entwicklungsgange, so z. B. die InseI Muraste in der Randzone des Nord-Estländischen Tafellandes, welche zur Ancyluszeit existierte, oder die Insel Vääna am Fuße des Glintes, welche am Anfang des Litorinastadiums $\left(\mathrm{L}_{\mathrm{I}}\right)$ als „Aufschüttungsinsel“ entstand und auf welche später $\left(\mathrm{L}_{\mathrm{II}}\right)$ das Geröllmaterial des Sedimentstromes längs der Küste aufgeschüttet wurde u. а. (Кессел, Раукас, 1967).

In vielen Fällen hat das Ausschleudern des Gesteinmaterials quer zur Küste recht lange ununterbrochen stattgefunden. So findet man in Kaugatuma eine ganze Serie Strandwälle (Orviku, 1934), die stufenweise auf geneigter Oberfläche der silurischen Kalksteine liegen: die höchsten liegen $12 \mathrm{~m}$ über dem gegenwärtigen Meeresniveau, die jüngsten entstehen an der gegenwärtigen Küste (Abb. 7). Sie bestehen aus Schotter, der seit den letzten Phasen des Litorinastadiums bis zur Gegenwart beständig von der Schorre ausgeschleudert wird.

Aus Geröllmaterial, welches auf der Schorre aus der Moräne ausgewaschen und quer zur Küste ausgeschleudert wurde, bestehen die Serien von Strandwällen in Kalana, welche sich stufenweise bis zu wenigstens $6 \mathrm{~m}$ in die Höhe erstrecken, u. a.

Beim Auftauchen der Inseln entstehen an ihren Küsten nach einiger Zeit vielfalls deutliche Sedimentströme der Küste entlang. Aus dem Gesteinmaterial diese- Ströme werden Strandwälle aufgeschüttet. Bei der weiter andauernden Hebung der Inseln entstehen immer neue Strandwälle, sie.umgeben die Insel wie Girlanden; dabei liegt jede jüngere Strandwallgirlande auf einem niedrigeren Niveau als die früher entstandenen. Solche Serien von Strandwällen entstanden an vielen Stellen des ebenen Tafellandes - da, wo die Abrasionsküste noch keine echte Steilküste bildete, sondern höchstens eine flache stufenartig in den Kalksteinen des Untergrundes gearbeitete Felsküste, welche für die Strandwälle das Gesteinmaterial lieferte.

Eine solche stufenartige Felsküste findet sich an einigen Stellen der gegenwärtigen Abrasionsküste der Insel Osmussaar, der Insel Väike-Pakri u. a. Ist die Entwicklung der Abrasionsküste so weit, daß ein Kliff entsteht, so können die alten Strandwälle, welche auf flachem Strande angehäuft wurden, bei fortdauernder Abrasion der Steilküste angegriffen werden.

Die ständige Entwicklung neuer Strandwälle konnte besonders da längere Zeit dauern, wo die Abrasionsküsten an den exponierten Stellen der Inseln oder Halbinseln Kliffe bildeten, welche für die Sedimentströme längs der Küste und für die Aufschüttung der Strandwälle fortwährend neues Material lieferten.

So entstand z. B. im Litorinameer die flache Felsinsel Mustjala, die sich durch andauernde Hebung mit dem Festlande vereinigte. An der exponierten Küste der Insel resp. Halbinsel entstand bald der Kliff, welcher bis heute Gesteinmaterial fürs Anhäufen der Strandwälle liefert. Gleichartiges Bild kann auch an anderen Stellen beobachtet werden, z. B. auf der Insel Esku, die im küstennahen Flachmeere des Baltischen Eisstausees lag (Möls, 1937 u. a.).

Auch in den ehemaligen Buchten fand eine ständige Entwicklung der Küsten statt, was man am Beispiel der Glintbuchten besonders gut sehen kann. In diesen Buchten findet man in verschiedenen Höhen eine ganze Reihe Sandküsten verschiedenen Alters, welche oft von niedrigen Stranddünen begleitet werden, zum Teil auch Geröllküsten, zum Teil als Nehrungen ausgebildet. Diese alten Sandküsten werden voneinander durch schmälere oder breitere sandbedeckte Streifen der Küstenebenen getrennt. So findet man eine Reihe solcher alter Sandküsten und niedriger Stranddünen: in der Glintbucht Lahepere, wo die ältesten in einer Höhe von $13 \mathrm{~m}$ liegen, 
die nächstjüngeren stufenartig immer niedriger bis zur Linie der heutigen Sandküste. Somit existierten in dieser Glintbucht die Bedingungen für die Entwicklung der Sandküsten wenigstens seit dem Anfang des Limneastadiums.

Für die Charakteristik der ständigen Entwicklung der Küsten im Estländischen Küstengebiet ist es zweckmäßig, auch der Entwicklung der Kliffe einige Aufmerksamkeit zu widmen.

Die Kliffe entstanden da, wo in der alten Oberflächengestaltung steilere, starkem Wellengang exponierte Hänge vorhanden waren. Dieses traf hauptsächlich für die nördlichen und nordwestlichen Abhänge der größeren oder kleineren Schichtterrassen zu. Bei solchen Bedingungen entstanden die Kliffe in der Vergangenheit an vielen Stellen und man findet sie auch an der gegenwärtigen Küste. Doch sind sie überall kurz und verhältnismäßig niedrig.

Vom Standpunkt der ständigen Entwicklung der Küste im Estländischen Küstengebiet ist es zweckmäßig, sich ein Bild von der Dauer der aktiven Entwicklung der Kliffe zu schaffen. Am besten ist dieses beim Nord-Estländischen Glint wahrnehmbar: der Glint ist die längste und höchste Steilküste Estlands, auch ist seine Entwicklung am gründlichsten erforscht worden (Tammekann, 1926, 1940; Öpik, 1927; Giere, 1932 u. a.).

$$
B_{\text {III }} \rightarrow 85
$$

$$
B_{\text {III }} \rightarrow 80
$$

\section{Ontika}

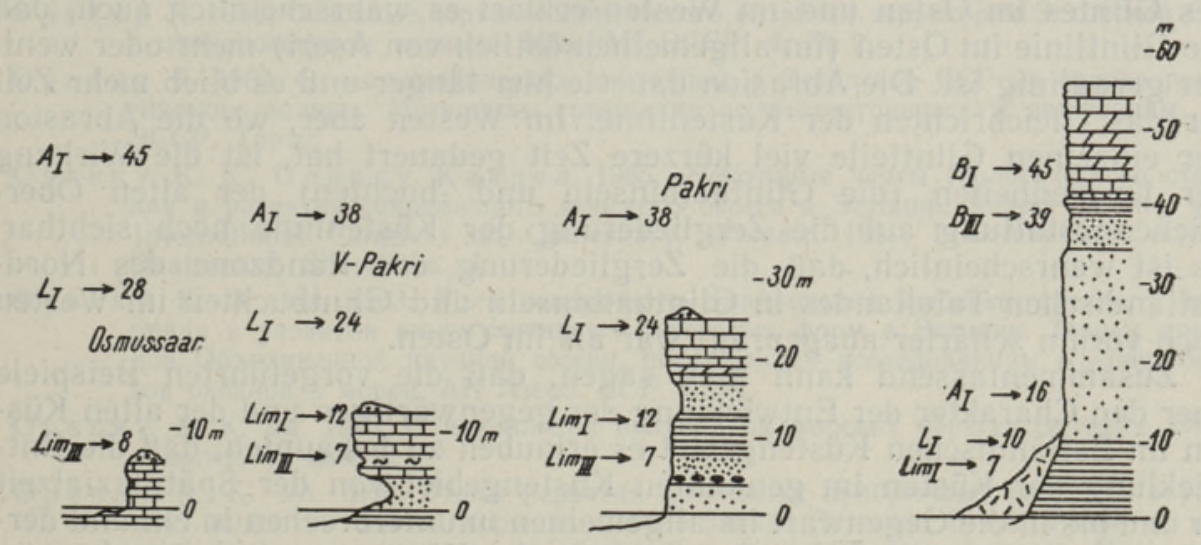

Abb. 8. Maximale Dauer der Abrasion des Nord-Estländischen Glintes auf Grund der Höhenlage der alten Küstenlinien, - bei Ontika, auf der Halbinsel Pakri, auf der Insel Väike-Pakri und auf der Insel Osmussaar.

Am imposantesten ist der Glint (Abb. 8) im östlichen Teil seiner Verbreitung zwischen Saka und Päite, wo er als eine fast ununterbrochenehohe Steilküste emporragt. Hier beträgt die absolute und relative Höhe des Glintes bis $56 \mathrm{~m}$ (Ontika). Als aktiver Abrasionskliff ist er hier nur in der Umgebung von Päite und etwas östlicher bei Utria ausgebildet. Im Westen ist die absolute Höhe des Glintes ungefähr $40 \mathrm{~m}$, die relative Höhe ist geringer; größtenteils ist der Glint hier bereits inaktiv. Nur im westlichsten Teil seiner Verbreitung ist er stellenweise noch aktiv, seine Höhe aber ist bereits viel kleiner - auf der Halbinsel Pakri $24 \mathrm{~m}$, auf der Insel Väike- 
Pakri $14 \mathrm{~m}$, auf der Inser Suur-Pakri noch weniger und, schließlich, auf der kleinen Insel Osmussaar nur noch $6 \mathrm{~m}$.

Vergleicht man die gegenwärtige abs. Höhe des Traufes der einzelnen Teile des Glintes mit der Höhe der alten Küstenlinien, so ergibt sich folgendes Bild (Abb. 8). Im Osten, wo der Glint am höchsten ist, ist er als Abrasionskliff am frühesten entstanden. Bei Ontika z. B., wo seine Höhe $56 \mathrm{~m}$ erreicht, existierte er als aktiver Kliff wahrscheinlich schon an der Küste des Baltischen Eisstausees - die maximale Höhenlage der Küstenlinie des letzteren ist hier etwa $45 \mathrm{~m}$ (Tammekann, 1926; Пярна, 1960). Als aktiver Kliff hat der Glint im Osten bis zur Gegenwart existiert - so ist es wenigstens bei Päite und Utria.

Im westlichen Teile des Glintes, wo seine absolute Höhe unter $40 \mathrm{~m}$ liegt und wo die spätglaziale und holozäne Hebung der Erdkruste schneller ver. lief, hat die Entwicklung des Glintes als Abrasionskliff viel später angefangen - auf der Halbinsel Pakri erst mit der zweiten Hälfte des Ancylusstadiums. Der Glint ist dann bis zur Gegenwart ununterbrochen aktiv gewesen; auf der Insel Osmussaar aber erst seit der zweiten Hälfte des Limneastadiums.

Man sieht, daß der Nordhang des Nord-Estländischen Tafellandes der alten Oberflächengestaltung für die beständige Entwicklung des Glintes als aktiver Kliff den Grund gegeben hat - im Osten hat der Glint an einigen Stellen 11000 Jahre als aktiver Kliff existiert - auf der Halbinsel Pakri - über 7000 Jahre, auf der Insel Osmussaar - ungefähr 2000 Jahre. Zugleich lag die Küstenlinie am Glint längere Zeit an ein und derselben Stelle, sie ist - je nach der Abrasion des Glintes - nur wenig in der Richtung des Festlandes verlegt worden. Der Unterschied in der Dauer der Abrasion des Glintes im Osten und im Westen erklärt es wahrscheinlich auch, daß die Glintlinie im Osten (im allgemeinen östlich von Aseri) mehr oder weniger geradlinig ist. Die Abrasion dauerte hier länger und es blieb mehr Zeit für das Gleichrichten der Küstenlinie. Im Westen aber, wo die Abrasion der einzelnen Glintteile viel kürzere Zeit gedauert hat, ist die Wirkung der Unebenheiten (die Glinthalbinseln und -buchten) der alten Oberflächengestaltung auf die Zergliederung der Küstenlinie noch sichtbar. Es ist wahrscheinlich, daß die Zergliederung der Randzone des NordEstländischen Tafellandes in Glinthalbinseln und Glintbuchten im Westen auch vorhin schärfer ausgeprägt war als im Osten.

Zusammenfassend kann man sagen, daß die vorgeführten Beispiele über den Charakter der Entwicklung der gegenwärtigen und der alten Küsten im Estländischen Küstengebiet es erlauben zu behaupten, daß die Entwicklung der Küsten im genannten Küstengebiet von der Spätglazialzeit an und bis in die Gegenwart im allgemeinen ununterbrochen in ein und derselben Richtung verlief. Die Entwicklung der Küsten wurde außer der tektonischen Hebung der Erdkruste noch von der alten Oberflächengestaltung, von den paläozoischen Gesteinen und den Quartärablagerungen beeinflußt. Der Charakter der betreffenden Einwirkungen ist an den gegenwärtigen Küsten erforscht und die erhaltenen Erfahrungen sind mit gutem Erfolg benutzt worden, die Beziehungen zwischen der Entwicklung der alten Küsten einerseits und der tektonischen Hebung, der alten Oberflächengestaltung und den alten Sedimenten andererseits festzustellen. 


\section{I T E R A T UR}

Elt e rm a n n G., R a u k a s A. 1966. Eesti luidetest. Eesti Loodus, nr. 1.

Gi e r e W., 1932. Morphologie der estländischen Nordküste. Veröffentlichungen des Geographischen Instituts der Albertus-Universität zu Königsberg i. Pr., N. F., Reihe Geographie, Nr. 6.

Kesse 1 H. 1961. Balti mere arenemisest Eesti NSV territooriumil holotseenis. ENSV TA Geol. Inst. Uurimused VII.

Möl s E. 1937. Esku rannamoodustused. Eesti Loodus 1937, nr. 5.

Orvik u K. 1933. Tuiskliiv. Tartu, Loodus.

Orviku K. 1934. Anseküla pinnaehitus. Koguteos «Eesti», kd. VIII. «Saaremaa». Tartu.

Orviku K., Orviku Kaarel 1961. Jooni Eesti tänapäevase ranniku geoloogiast. ENSV TA Geol. Inst. Uurimused VII.

T a mmekann A. 1926. Die Oberflächengestaltung des Nordestländischen Küstentafellandes. Acta Univ. Tartu, A. 9, nr. 7.

T a m mek a n A. 1940. The Baltic Glint. Morphography of the Glint. A Geomorphological Study. Eesti Loodusteaduste Arhiiv, seeria 1, kd. 11, vihk 3-4.

Opik A. 1927. Die Inseln Odensholm und Rogö. Ein Beitrag zur Geologie von NW Estland. Acta Univ. Tartu, A. 12, nr. 2.

Желнин Г. А. 1964. Точность и возможности метода повторного нивелирования. Современные и новейшие движения земюой коры в Прибалтике. АН Лит. ССР, отд. географни. Вильнюс.

Кессел Х. 1961. Древние береговые образования бассейна Балтийского моря в Эстонской ССР. Тр. Ин-та геол. АН ЭССР, VIII.

Кессел Х., Р аукас А. 1967. Прибрежные отложения Анцилового озера и Литоринового моря в Эстонин. Ин-т геэл. АН ЭССР. Таллин.

М и й дел А. 1966. О связи между современными движениями земной коры и эрозионно-аккумулятивной деятельностью рек Эстонии. Изв. АН ЭССР. Сер. физ.матем. и техн. наук, 15, № 1 .

О р в и к у К. 1955. Основные черты геологического развития территории Эстонской ССР в антропогеновом периоде. Изв. АН ЭССР, 4, № 2.

О р в и ку К. 1960. О неотектонических двнжениях в Эстонской ССР на основе геологических данных. Материалы совещания по неотектоническим движениям. АН̈ ЭССР. Тарту.

Орвику К. К., Орвику К а арел. 1965. Некоторые черты геологического строения и развития современного морского берега в Эстонии. Report of the VIth International Congress on Quaternary, Warsaw, 1961, I. Commission on the Quaternary Shorelines. I.

О р в и ку К. К. мл. 1963. Роль поперечного перемещения щебнево-галечного материала в развитии аккумулятивных береговых форм в Эстонии. Тезисы докладов Объединенной научной сессии, посвященной исследованиям Каспия, берегов океанов и морей. АН Азерб. ССР. Баку.

О р в и ку К. К. мл. 1965. О накоплении валунов на морских берегах Эстонии. Океанология, V, вып, 2.

О рв и ку К. К. мл. 1966. Этапы развития небольших прибрежных островов в условиях поднятия земной коры на Северо-Западе Эстонии. В сб.: Развитие морских берегов в условиях колебательных движений земной коры. Ин-т. геол. АН ЭССР. Таллин.

П я рна К. 1960. Геология Балтийского приледникового озера и больших местных приледниковых озер на территории Эстонин. Тр. Ин-та геол. АН ЭССР, V.

Р аукас А., Кессел Х., Эльтерманн Г. 1965. Строение древних аккумулятивных береговых форм в Эстонии. В сб.: Литология и стратиграфия четвертичных отложений Эстонии. Ин-т. геол. АН ЭССР. Таллин.

\section{Institut für Geologie}

der Akademie der Wissenschaften der Estnischen SSR 


\section{K. ORVIKU, K. ORVIKU jun.}

\section{RANDADE KUJUNEMISE PUSIVAST ISELOOMUST EESTI RANNIKUALAL HILISJÄÄAJAST NOODISAJANI}

Randade kujunemist Eesti rannikualal mōjustanud tingimused, nagu maakoore summaarne kerkimine, vana reljeef, paleosoilised kivimid ja kvaternaarsed setted, on kogu vaadeldava aja vältel ja kogu vaadeldava ala piirides olnud üldiselt ühesugused ja vastavalt sellele on käsitletaval alal ka randade kujunemine olnud üldiselt ühesuunaline.

Maakoore summaarse kerkimise tōttu Eesti rannikualal (joon. 1) satuvad lainetuse mõjupiirkonda aiva uued merepōhja vöötmed, mıs aga juba peatselt üle merepinna kerkivad. Niisugustes tingimustes ei ole siin tavaliselt kujunenud suuri murrutusvorme, suuri settevoole ega suuri kuhjevorme rannal. Ole veepinna kerkivate alade randasid iseloomustab algul veealuse rannanōlva murrutamine ja setete kuhjumine rannavöötmele ristí rannale (joon. 4).

Oldiselt tasane, kergelt lainjas vana reljeef on mõjustanud Eesti rannikuala randade ühesuunalist kujunemist. Eesti rannikuala iseloomustavad vaade!daval ajal laugrannad, rannajoone suur sopilisus, rohkete saarte ja madalate esinemine rannalähedases madalas meres (joon. 2, 3), mis omakorda on alati pōhjustanud üheaegselt esinevate rannaerimite kiiret vahelduvust. Kogu vaadeldava aja văltel on Eesti rannikualal rannajoone sopilisıs. väga piiratult õgvendunud.

Sōltuvalt pôhimoreeni laialdasest levikust kvaternaarsete setete hulgas on alati väga laialt levinud moreenirannad, mida iseloomustavad kivisillutised (joon. 5) ja ajujääst kuhjatud rändrahnude vallid (joon. 6). Küllalt suurtel aladel on Eesti rannikua'al kvaternaarsete setete paksus sedavõrd väike olnud, et see on lainetusega randadel täiesti hävitatud ja vastavalt on murrutamisele allunud pealiskorra kivimid. Sellest kōnelevad nii vanad kui ka nüüdisaegsed kaljurannad ja klifid.

Tänu vana reljeefi tasasusele ja makoore pidevale kerkimisele on Eesti rannikua'al paljudes rohkem piiratud lōikudes ranna iseloom püsinud muutmatult pikemat aega. Nii on Kaugatuma ümbruses püsinud astmeline kaljurand ja kliburannavallide kuhjumine selle astmetele materjali risti rannale paiskamise korras katkestamatult litoriina staadiumi lôppfaasidest kuni nüüdisajani (joon. 7). On küllalt näiteid selle kohta, et saarte ja poolsaarte külgede'e on pikemat aega pidevalt kuhjatud klibu-rannavalle, milledest iga noorem. asub eelnevalt tekkinust mōnevōrra madalamal. Ka omaaegsete lahtede piirides on toimunud sageli pikemat aega ühesuunaline randade kujunemine.

Randade ühesuunalisest kestvast kujunemisest Eesti rannikuala rohkem piiratud lōikudes kōneleb se!gelt ka ühe vōi teise klifi kujunemise kestus. Seda on parimalt võimalik. illustreerida Pōhja-Eesti paekalda kliffide kujunemise kestuse näitega (joon. 8). Kui paekalda idaosas algas tema kui murrutusjärsaku kujunemine kohati juba hilisjääajal ja on pidevalt kestnud nüüdisajani, siis paekalda lääneosas on tema eri :öigud kerkinud üle merepinna ja hakanud kui klifid kujunema tunduvalt hiljem.

Lähtudes sellest, et Eesti rannikualal on randade kujunemine olnud hilisjääajast kuni nüüdisajani ühesuunaline, vōib nüüdisaegsete randade kujunemise iseloomu lugeda. pärituks.

\section{К. ОРВИКУ, К. ОРВИКУ мл.}

\section{О ПОСТОЯНСТВЕ ХАРАКТЕРА РАЗВИТИЯ БЕРЕГОВ НА ЭСТОНСКОМ ПОБЕРЕЖЬЕ С ПОЗДНЕЛЕДНИКОВОГО ДО СОВРЕМЕННОГО ВРЕМЕНИ}

Природные условня, влиявшие на развитие берегов Эстонского побережья, - климатическая обстағовка, суммарное поднятие земной коры, древний рельеф, древнепалеозойские осадочные породы, четвертичные отложения - в течение всего рассматриваемого времени на всей рассматриваемой территории были в общем одинаковыми. Соответственно однонаправленным был и характер развития берегов.

Под влиянием суммарного поднятия земной коры (рис. 1) на Эстонском побережьев сферу волновой деятельности вовлекаются все новые полосы морского дна, которые уже через короткое время превращаются в сушу. В таких условиях здесь обычно крупных абразнонных форм, крупных потоков наносов и крупных аккумулятивных фсрм не образовалось. Для вновь возникающих берегов характерны размыв подводного берегового склона и донное питание аккумулятивных форм (рис. 4).

В общем ровный и лишь слегка волнистый древний рельеф, образовавшийся уже в дочетвертичное время и преобразованный в плейстоцене деятельностью материкового льда, способствовал однонаправленному развитию поднимающихся берегов Эстонского побережья. Берега в этом районе всегда были отмелые, береговая линия сильно рас- 
членена; для прибрежного мелководного моря характерно наличие многочисленных островов и отмелей (рис. 2,3 ). Все это со своей стороны обусловило быструю перемежаемость одновременно существовавших разновидностей берега. В течение рассматриваемого времени первичная расчлененность береговсй линии, обусловленная древним рельефом, выровнялась незначитәльно, что объясняется кратковременным воздействием береговых процессов на определенную береговую полосу.

На сравнительно больших участках Эстонского побережья мощность четвертичных отложений была столь незначительной, чтс они во многих местах полностью размывались волнами и воздействию волн подвергались уже коренные породы, о чем свидетельствуют как современные, так и древниє скальные берега и клифы. Как в настоящее время, так и в прошлом были широко распространены моренные берега с характерными для них каменными мостовыми (рис. 5) и грядами эрратических валунов, нагроможденных морским льдом (рис. 6).

Из-за равнинности древнего рельефа и постоянного поднятия земной коры на многих более ограниченных участках Эстонского побережья характер берега оставался некзменным в течение длительного времени. Так, в окрестностях Каугатума развитие ступенчатого скального берега и нагромождение щебневых береговых валов донного питания продолжается беспрерывно уже начиная с последних фаз литориновой стадии вплоть до современного времени (рис. 7). Имеется много примеров беспрерывного накопления щебневых береговых валов на боковых берегах островов и полуостровов, причем каждый новый береговой вал расположен ниже ранее образовавшегося. Для примера можно указать на разновозрастные аккумулятивные береговые формы полуостүова Мустъяла. Непрерывное однонаправленное развитие берегов происходило и в пределах древних заливов. Например, в глинтовой бухте Лахепере формирование песчаных берегов началось в лимниевой стадии и продолжается в настоящее время.

О длительном однонаправленном развитии берегов на более ограниченных участках Эстонского побережья свидетельствует продолжительность развития того или другого клифа. Это наглядно подтверждается и на примере клифов Северо-Эстонского глиғта (рис. 8). Если в восточной части развитие глинта как абразионного обрыва началось местами уже в позднеледниковье и прсдолжается беспрерывно до настоящего времени, то в западной части отдельные участки глинта поднялись выше уровня моря и стали развиваться в качестве клифов значительно позже.

Приведєнные примеры свидетельствуют с достаточной ясностью о том, что на Эстсғском побережье раззитие разновозрастных береговых образований происходило ғачиная с позднеледникового до современного времени однонаправленно. Из этого можно сделать вывод, что характер развития современного берега Эстонского побережья является унаследованным. 